Steuerberater-Jahrbuch 2018/2019 



\title{
Steuerberater-Jahrbuch 2018/2019
}

\author{
zugleich Bericht \\ über den 70. Fachkongress der Steuerberater \\ Köln, 30. und 31. Oktober 2018
}

Herausgegeben
im Auftrag des Fachinstituts der Steuerberater von

Prof. Dr. Thomas Rödder

Steuerberater, Wirtschaftsprüfer
Prof. Dr. Rainer Hüttemann

Universitätsprofessor

\section{ottoschmidt}




\section{Zitierempfehlung:}

Verfasser, StbJb. 2018/2019, Seite ...

Bibliografische Information

der Deutschen Nationalbibliothek

Die Deutsche Nationalbibliothek verzeichnet diese

Publikation in der Deutschen Nationalbibliografie;

detaillierte bibliografische Daten sind im Internet über http://dnb.d-nb.de abrufbar.

Verlag Dr. Otto Schmidt KG

Gustav-Heinemann-Ufer 58, 50968 Köln

Tel. 02 21/9 37 38-01, Fax 02 21/9 37 38-943

info@otto-schmidt.de

www.otto-schmidt.de

ISSN 0081-5519

ISBN 978-3-504-62665-5

@ 2019 by Verlag Dr. Otto Schmidt KG, Köln

Das Werk einschließlich aller seiner Teile ist urheberrechtlich geschützt. Jede Verwertung, die nicht ausdrücklich vom Urheberrechtsgesetz zugelassen ist, bedarf der vorherigen Zustimmung des Verlages. Das gilt insbesondere für Vervielfältigungen, Bearbeitungen, Übersetzungen, Mikroverfilmungen und die Einspeicherung und Verarbeitung in elektronischen Systemen.

Das verwendete Papier ist aus chlorfrei gebleichten Rohstoffen hergestellt, holz- und säurefrei, alterungsbeständig und umweltfreundlich.

Satz: WMTP, Birkenau

Druck und Verarbeitung: Kösel, Krugzell

Printed in Germany 